\title{
Licenciados no Curso de Medicina: Motivações, Socialização e Reconhecimento Académico
}

\author{
Graduate Students in Medicine Course: Motivation, \\ Socialization and Academic Recognition
}

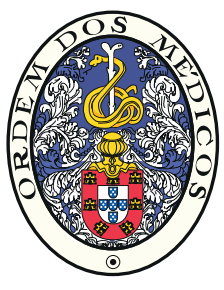

Cristina MAGALHÃES-ALVES $\rrbracket^{1}$, Joselina BARBOSA ${ }^{1}$, Laura RIBEIRO ${ }^{1,2}$, Maria Amélia FERREIRA ${ }^{1}$ Acta Med Port 2017 Apr;30(4):285-292 - https://doi.org/10.20344/amp.8400

RESUMO

Introdução: Os estudantes com uma licenciatura prévia têm experiências pessoais e profissionais que contribuem para um percurso académico diferente no curso de medicina. Este estudo tem como objetivos: 1) avaliar a satisfação e o impacto do reconhecimento académico; 2) investigar se a motivações e expetativas de ingresso se mantêm ao longo do curso; 3) avaliar a socialização no regresso ao ensino superior.

Material e Métodos: Para o primeiro objetivo foi administrado um questionário a 82 estudantes que ingressaram na Faculdade de Medicina da Universidade do Porto nos anos letivos de 2011/2012 a 2013/2014. Para o segundo e terceiro objetivos foi usado um focus group (três grupos de cinco estudantes cada, representativos dos três anos letivos).

Resultados e Discussão: Os estudantes sentiram-se satisfeitos com o reconhecimento, sendo que $50 \%$ afirmaram que as creditações substituem o conhecimento que iriam adquirir ao realizar as unidades curriculares e $47 \%$ preferiram obter creditação. $O$ sucesso académico associou-se negativamente com a satisfação do reconhecimento e positivamente com a idade, formação anterior e ciclo de inscrição. A socialização destes estudantes é distinta dos mais jovens, as suas motivações de ingresso são intrínsecas e mantêm-se ao longo do curso contrariamente às suas expectativas.

Conclusão: Os estudantes preferem o reconhecimento à realização de unidades curriculares. Os mais satisfeitos com o reconhecimento realizam menos créditos e os mais jovens, da área da saúde e inscritos no ciclo clínico, realizam mais. Ao longo do curso, as motivações tornam-se mais sólidas, as expectativas mudam e a socialização é realizada com maior responsabilidade.

Palavras-chave: Educação Médica; Escolha da Profissão; Faculdade de Medicina; Motivação; Socialização

\section{ABSTRACT}

Introduction: Students with a previous degree have personal and professional experiences that can contribute to a different academic path during the medical course. This study aims to: 1) analyze both satisfaction and impact of academic recognition; 2) investigate whether motivations and expectations at entrance are maintained along the course; 3 ) to evaluate socialization after regress to higher education.

Material and Methods: To accomplish the first objective a questionnaire was administered to 82 students who entered the medical school from 2011/2012 to 2013/2014. For the second and third goals a focus group was run (three groups with five students each, representing the three academic years).

Results and Discussion: Students felt satisfied with the recognition, and $50 \%$ of them believe that accreditations replace knowledge acquired with the curricular units, and $47 \%$ preferred to obtain accreditation. Academic achievement was negatively associated with the satisfaction of recognition and positively with age, background and registration cycle. Socialization of these students is distinct from the younger ones, their motivations at entrance are intrinsic and, contrary to expectations, are maintained along the course.

Conclusion: Students prefer recognition instead of attending the curricular units. The most satisfied with the recognition accomplish less credits and the younger ones, from health area and enrolled in the clinical cycle, accomplish more. Along the course, motivations become more solid, expectations change and socialization is carried out with greater responsibility.

Keywords: Career Choice; Education, Medical; Faculty, Medical; Motivation; Socialization

\section{INTRODUÇÃO}

$\mathrm{O}$ ingresso no curso de medicina da Faculdade de Medicina da Universidade do Porto (FMUP) por estudantes que já detêm um grau académico (licenciatura), originou um elevado interesse em estudar o perfil deste contingente de acesso, quer pela escassez de informação, quer pelo recurso ao reconhecimento de formação anterior destes estudantes, o que leva a um percurso académico díspar dos restantes estudantes que ingressaram pela primeira vez no ensino superior.

Este trabalho tem três objetivos: analisar qual o impacto do reconhecimento na aprendizagem e no sucesso académicos desses estudantes, que constituem um contingente muito distinto da população discente, apurar se as suas motivações e expetativas de ingresso estão a ser correspondidas, e de que forma as suas vivências no meio académico poderiam contribuir ou influenciar na educação médica e na socialização destes futuros médicos.

\section{Concurso especial para acesso ao curso de Medicina por titulares de licenciatura \\ No caso dos cursos de medicina em Portugal e cumprindo o Decreto-Lei n. ${ }^{\circ} 40 / 2007^{1}$ foi imposta a}

1. Unidade de Investigação e Desenvolvimento Cardiovascular (Porto). Departamento de Ciências da Saúde Pública e Forenses e Educação Médica. Faculdade de Medicina. Universidade do Porto. Porto. Portugal.

2. I3S - Instituto de Investigação e Inovação em Saúde. Departamento de Ciências da Saúde Pública e Forenses, e Educação Médica. Faculdade de Medicina. Universidade do Porto. Porto. Portugal.

$\square$ Autor correspondente: Cristina Magalhães Alves. sevla@med.up.pt

Recebido: 31 de outubro de 2016 - Aceite: 31 de dezembro de 2016 | Copyright @ Ordem dos Médicos 2017 
obrigatoriedade da abertura de vagas para o concurso especial de acesso a titulares do grau de licenciado a partir do ano letivo 2007/2008, aquando da implementação do Processo de Bolonha no Ensino Superior em Portugal. As vagas deste concurso são fixadas anualmente por despacho reitoral, cumprindo o estipulado como número mínimo de vagas, sendo $15 \%$ do numerus clausus dos cursos das várias faculdades a partir do ano letivo de 2011/2012.

\section{Caraterização do processo de creditação de formação anterior}

Numa perspetiva de política educativa, o Processo de Bolonha teve início informal em maio 1998, com a Declaração de Sorbonne, e arrancou oficialmente com a Declaração de Bolonha, ${ }^{2}$ a qual definiu um conjunto de etapas e de passos a dar pelos sistemas de ensino superior europeus, no sentido de construir um espaço europeu de ensino superior globalmente harmonizado.

Um dos aspetos mais relevantes da Declaração de Bolonha é a proposta de generalização de um sistema de créditos - European Credit Transfer and Accumulation System (ECTS), criado pela Comissão das Comunidades Europeias, com o objetivo de gerar procedimentos comuns que garantissem o reconhecimento da equivalência académica dos estudos nos vários países.

Para o efeito, a Universidade do Porto assentou as regras deste processo num regulamento próprio, Despacho n. ${ }^{0} 12722 / 2003$ de 4 de outubro, ${ }^{3}$ onde consta que no caso de creditação de formação anterior os referidos processos podem ocorrer no âmbito da formação conferente de grau, designadamente nos ciclos de estudos conducentes ao grau de licenciado, de mestre e de doutor, bem como, em casos considerados de inequívoca relevância, no âmbito da educação contínua.

No caso de experiência profissional, a atribuição global do número de créditos ECTS deve resultar de uma avaliação em que sejam considerados os conhecimentos dos estudantes, o seu nível e adequação às áreas científicas do ciclo de estudos, a sua atualidade e as competências demonstradas.

\section{Motivação e socialização}

Que razões levam estes licenciados a regressar ao ensino superior e a escolher a área de medicina, quando muitos deles já exercem uma profissão na sua formação de base?

Podemos assim referir dois tipos de motivação: a motivação intrínseca, também chamada de motivação pessoal ou inconsciente, em que o indivíduo realiza determinada atividade pela própria causa, por considerá-la interessante, atraente ou geradora de satisfação; A motivação extrínseca ou consciente são os fatores motivacionais externos, traduzidos em recompensas que proporcionam a satisfação ou o prazer que a tarefa em si não proporciona. ${ }^{4}$

Segundo Pinto (2001) 5 a motivação envolve um conjunto de processos internos que impele o organismo a satisfazer uma necessidade, isto indica que o fator inicial tanto pode ser uma necessidade biológica como a fome ou uma necessidade social como o desejo de ser estimado e aceite pelos outros.

A socialização destes estudantes licenciados no seu retorno ao ensino superior será distinta dos restantes colegas de curso?

A socialização é o processo pelo qual as pessoas adquirem conhecimentos, competências e disposições que se tornem mais ou membros menos eficazes de sua sociedade. ${ }^{6}$

A socialização é um "processo biográfico de incorporação das disposições sociais vindas não somente da família e da classe de origem, mas também do conjunto dos sistemas de ação com os quais o indivíduo se cruzou no decorrer da sua existência". ${ }^{7}$

De acordo com John C. Weidman (2006) a socialização do ensino superior pode ser concebido como uma série de processos em que o estudante: 1) Se integra numa instituição de ensino superior com certos valores, aspirações e outros objetivos pessoais; 2) É exposto a várias influências socializadoras, incluindo pressões normativas exercidas através de: a) Relações sociais com professores e colegas; b) Pressões da família; c) $O$ envolvimento com grupos de referência fora da instituição; 3) Avalia a relevância das várias pressões normativas encontradas para atingir objetivos pessoais; 4) Altera ou mantém esses valores, aspirações e objetivos pessoais que foram realizados no acesso ao curso de medicina. $O$ autor identifica ainda três processos na socialização: a) a interação interpessoal; b) a interação intrapessoal; c) a integração. Estes três processos têm como exemplos a interação entre estudante e docente, o estudo e frequência das aulas e a vida académica e social, respetivamente. Obtendo um conjunto de resultados: a) a aquisição de conhecimento; b) a aquisição de competências; c) a aquisição de disposições como a afetividade. ${ }^{8}$

Para responder aos objetivos formulados e às questões que são colocadas - a formação académica de um licenciado que ingressa num curso de medicina influencia o sucesso e a socialização académica? As motivações e expectativas de ingresso serão correspondidas ao longo do curso? - o estudo desta população de estudantes incidiu sobre a análise das suas motivações, expectativas, vivências e até que ponto o reconhecimento da formação académica anterior influência o percurso académico no curso de medicina.

\section{MATERIAL E MÉTODOS}

A metodologia híbrida ocorre em casos correspondentes à existência de um único estudo em que a respetiva metodologia engloba, fundidos nesse estudo, elementos quantitativos e qualitativos. ${ }^{6}$

Foi com base nesta metodologia que a investigação foi desenvolvida, conciliando as metodologias quantitativa e qualitativa tornando-as complementares com vista ao enriquecimento do estudo, estabelecendo dois momentos para a recolha de dados.

No primeiro momento, foi realizado um inquérito por questionário, o qual foi distribuído para preenchimento presencial em sala de aula, à totalidade dos estudantes que requereram o reconhecimento por créditos e que ingres- 
saram pelo regime de titulares de licenciatura. Com este questionário foram analisados três aspetos: a) satisfação com o processo de reconhecimento por creditação; b) fatores associados com o número de créditos realizados durante a primeira inscrição no curso; c) preferência dos estudantes pelo reconhecimento à realização das UC no currículo de medicina da FMUP.

O estudo contemplou uma amostra com 82 estudantes, sendo 63 do género feminino e 19 do género masculino, entre os 22 e os 41 anos de idade; $60 \%$ destes estudantes são provenientes de uma formação académica anterior nas áreas da saúde, $45 \%$ concluiu a licenciatura e $27 \%$ concluiu o mestrado integrado (Tabela 1).

As variáveis categóricas foram sumariadas com frequências absolutas ( $n$ ) e relativas (\%). A informação dos itens que descrevem a satisfação com o processo de creditação foi resumida através de análise fatorial exploratória (AFE) pelo método de componentes principais com rotação Varimax.

Para avaliar fatores associados ao sucesso académico utilizou-se o modelo linear geral simples e ajustado. As variáveis que apresentaram um valor de $p<0,20$ no modelo simples foram incluídas na análise multivariada. Foram testadas algumas interações sem efeito significativo. A força da associação foi descrita através do coeficiente beta e respetivo intervalo de confiança calculados pelo método bootstrap. Os dados foram analisados no software SPSS (Statistical Package for Social Sciences) versão 22.0. A significância estatística foi avaliada pelo valor de $p \leq 0,05$.

Tabela 1 - Caraterização dos estudantes licenciados

\begin{tabular}{lc}
\hline Variáveis & $\mathbf{n}(\%)$ \\
\hline Género & $63(76,8)$ \\
Feminino & $19(23,2)$ \\
Masculino & $29(4,3)$ \\
Idade & $30(36,6)$ \\
22 a 25 & $26(31,7)$ \\
26 a 29 & $26(31,7)$ \\
30 a 41 & \\
Habilitações & $37(45,1)$ \\
Licenciatura & $22(26,8)$ \\
Mestrado integrado & $13(15,9)$ \\
Mestrado & $10(12,2)$ \\
Doutoramento/Pós-doutoramento & \\
Área científica & $60(73,2)$ \\
Ciências da saúde & $8(9,8)$ \\
Ciências tecnológicas & $13(15,9)$ \\
Ciências naturais & $1(1,2)$ \\
Ciências exatas & $27(32,9)$ \\
Ano letivo de ingresso & $28(34,1)$ \\
$2011 / 12$ & $27(32,9)$ \\
$2012 / 13$ &
\end{tabular}

No segundo momento foi aplicada a técnica qualitativa focus group. Segundo Krueger e Casey (2009) a intenção do focus group é a de promover auto-revelação entre os participantes havendo condições para alcançar tal propósito quando os participantes se sentem confortáveis, respeitados e livres para expressarem a sua opinião. ${ }^{9}$

Para a realização do focus group, foram criados três grupos correspondentes aos três anos letivos que são alvos deste estudo, com cinco estudantes cada, escolhidos aleatoriamente da amostra anteriormente descrita. Para aumentar a eficácia deste processo, há a considerar a relevância de uma 'equipa de moderadores': a) um moderador, que teria como principal missão a condução e a manutenção da discussão e, b) um auxiliar de moderação, cujas principais tarefas seriam a gestão do equipamento de gravação, estar atento às condições logísticas e do ambiente físico, dar resposta a interrupções inesperadas e tomar notas sobre a discussão do grupo. Neste âmbito, neste estudo as entrevistas foram conduzidas por dois moderadores sem qualquer ligação com os estudantes. ${ }^{9,10}$

Foram realizadas três entrevistas semiestruturadas, orientadas pelo respetivo guião constituído por três temas, com duração média de 90 minutos. ${ }^{11}$ As entrevistas foram gravadas com o consentimento, devidamente assinado, de cada estudante.

Segundo Grbich (1999) esta técnica tem como objetivo primordial a identificação de perceções, sentimentos, atitudes e ideias dos participantes a respeito de um determinado assunto, produto ou atividade. ${ }^{12}$

Para Morgan (1996, 1997), focus group é uma técnica de investigação de recolha de dados através da interação do grupo sobre um tópico apresentado pelo investigado que comporta três componentes essenciais: os focus group são um método de investigação dirigido à recolha de dados; localiza a interação na discussão do grupo como a fonte dos dados; e, reconhece o papel ativo do investigador na dinamização da discussão do grupo para efeitos de recolha dos dados. ${ }^{11,13}$

Em relação à análise de conteúdo, esta decorre ao longo de três etapas: 1) codificação/indexação: uma vez transcrito e (re)lido o texto, ocorre um processo de atribuição de categorias (e, se necessário, de subcategorias) refletindo estas os temas presentes no guião bem como os novos que emergiram da discussão dos grupos; 2) armazenamento/recuperação: esta fase é dedicada à compilação de todos os extratos do texto subordinados à mesma categoria de modo a poder compará-los; 3) interpretação: deve ser suportada numa análise sistemática dos dados, podendo esta fazer uso de métodos específicos de análise como o método de indução analítica. ${ }^{14}$

Foi realizada uma análise de conteúdo categorizado, com base nos temas três temas do guião de entrevista: 1) os motivos de ingresso no curso de medicina e a escolha da FMUP: 2) relação com colegas e docentes e comparação das motivações e expectativas de ingresso: 3) o impacto das creditações obtidas no percurso académico, respeitando a sua ordenação e cumprindo as etapas anteriormente descritas. 


\section{RESULTADOS e DISCUSSÃO Inquérito por questionário}

Podemos verificar que os estudantes encontram-se satisfeitos com a instrução do referido processo $(48,4 \%)$, o mesmo aconteceu com o prazo para a requisição $(42,2 \%)$, com a avaliação e respetiva concessão $(37,5 \%)$, com o tempo de resposta $(35,9 \%)$ e principalmente com o número de créditos obtidos $(50 \%)$.

No entanto, nas várias categorias por nível de satisfação os valores são relativamente constantes, o que revela uma importante solidificação da opinião da satisfação dos estudantes (Tabela 2).
Com vista a conhecer a estrutura relacional dos itens que descrevem a satisfação do processo de creditação, foi realizada a análise de componentes principais.

A solução fatorial inclui um fator que explica $48,2 \%$ da variância total e pesos fatoriais que variam de 0,498 a 0,854 . A consistência interna foi de 0,715 (Tabela 3).

Analisamos a satisfação dos itens do processo de creditação tendo em conta o género e idade dos estudantes. Apesar de a satisfação mediana nos homens ser inferior $(57,5$ vs 61,3$)$, não se verificaram diferenças significativas $(p=0,284)$ entre o género e a idade (Fig. 1).

Em relação aos fatores associados com o número de

Tabela 2 - Satisfação com o Reconhecimento por Creditação

\begin{tabular}{|c|c|c|c|c|c|}
\hline \multirow[b]{2}{*}{ Itens } & \multicolumn{5}{|c|}{ n (\%) } \\
\hline & $\begin{array}{l}\text { Muito } \\
\text { insatisfeito }\end{array}$ & Insatisfeito & $\begin{array}{l}\text { Nem satisfeito/ } \\
\text { Nem insatisfeito }\end{array}$ & Satisfeito & $\begin{array}{l}\text { Muito } \\
\text { satisfeito }\end{array}$ \\
\hline $\begin{array}{l}\text { Com o formulário de instrução do } \\
\text { processo }\end{array}$ & $2(3,1)$ & $9(14,1)$ & $13(20,3)$ & $31(48,4)$ & $9(14,1)$ \\
\hline Com o prazo para requerer o processo & $5(7,8)$ & $14(21,9)$ & $9(14,1)$ & $27(42,2)$ & $9(14,1)$ \\
\hline $\begin{array}{l}\text { Com a avaliação e respetiva } \\
\text { concessão de creditações }\end{array}$ & $4(6,3)$ & $16(25,0)$ & $8(12,5)$ & $24(37,5)$ & $12(18,8)$ \\
\hline $\begin{array}{l}\text { Quanto ao tempo de resposta entre o } \\
\text { início e o fim do processo }\end{array}$ & $2(3,1)$ & $15(23,4)$ & $12(18,8)$ & $23(35,9)$ & $12(18,8)$ \\
\hline Com o número de créditos obtidos & $4(6,3)$ & $15(23,4)$ & $9(14,1)$ & $32(50,0)$ & $4(6,3)$ \\
\hline
\end{tabular}

Tabela 3 - Pesos fatoriais e consistência interna dos itens

\begin{tabular}{lc}
\hline Itens & Carga fatorial \\
\hline Com o formulário de instrução do processo & 0,663 \\
Com o prazo para requerer o processo & 0,498 \\
Com a avaliação e respetiva concessão de creditações & 0,854 \\
Quanto ao tempo de resposta entre o início e o fim do processo & 0,534 \\
Com o número de créditos obtidos & 0,842 \\
\% Variância explicada & 48,2 \\
Valor próprio & 2,4 \\
a Cronbach & 0,715 \\
Pontuação total, mediana (p25 - p75) & $60(50-70)$ \\
\hline
\end{tabular}

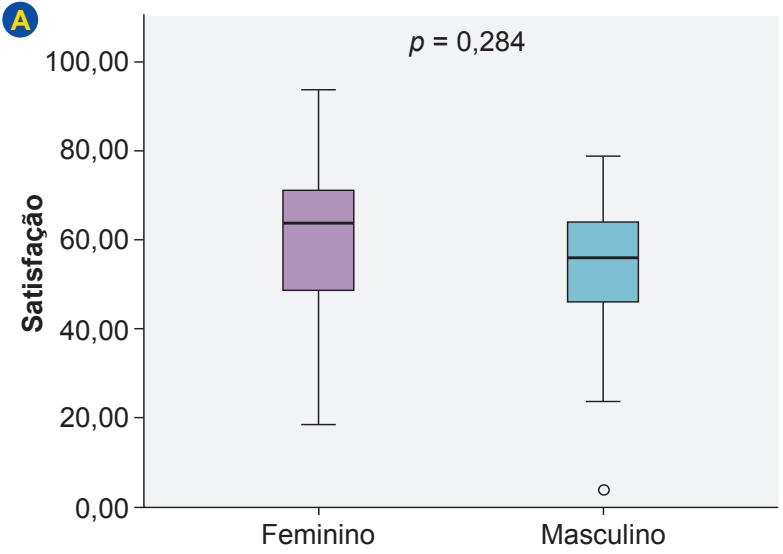

Género

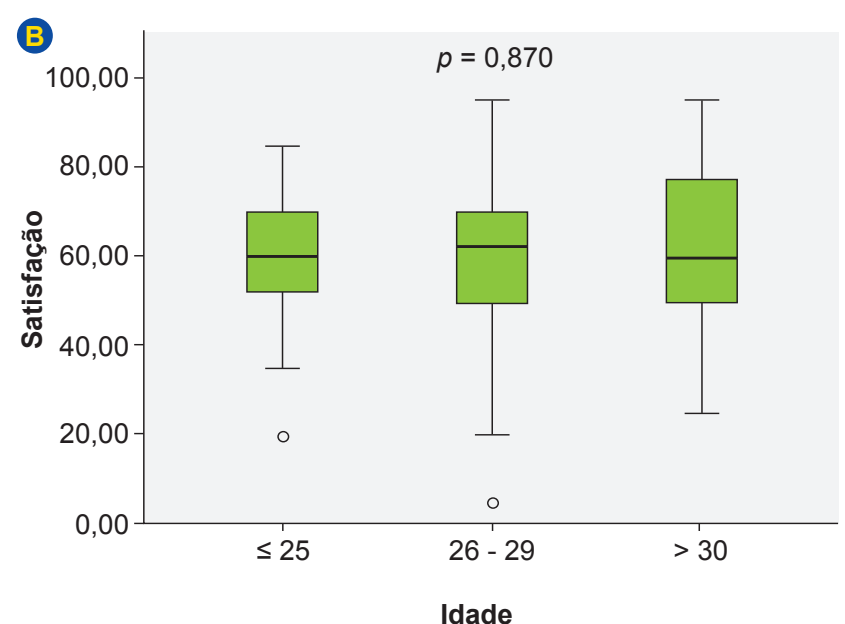

Figura 1 - Distribuição do domínio satisfação com o processo de creditação por género (A) e por idade (B) 
créditos realizados durante o primeiro ano de inscrição no curso, vários itens foram avaliados, idade, género, créditos obtidos, satisfação com o processo de creditação, satisfação com os créditos obtidos, ano letivo, ciclo de inscrição, grau académico e área de formação anterior.

A análise univariada revelou que apenas seis das variáveis estudadas - idade, género, satisfação com os créditos obtidos, ano letivo, ciclo de inscrição, grau académico e área da saúde - apresentaram associação significativa com o número de créditos realizados. A regressão multivariada mostrou que apenas a idade, a satisfação com os créditos obtidos, o ciclo de inscrição e a área da saúde mantiveram um efeito significativo. Quem está satisfeito com os créditos obtidos por reconhecimento realiza menos créditos no curso de medicina, quem é mais jovem, proveniente de formação anterior na área da saúde e se inscreve no ciclo clínico realiza mais créditos em medicina (Tabela 4).

Tendo em conta a preferência dos estudantes pelo reconhecimento por creditação à realização das UC no currículo de Medicina da FMUP (Tabela 5), constata-se que $50 \%$ dos estudantes afirmam que as creditações obtidas substituem o conhecimento que obteriam se realizasse as unidades curriculares na FMUP e, confirmando esta afirmação, $46,9 \%$ dos estudantes preferem obter creditação, em vez de realizar as UC na FMUP.

Para estes estudantes, o grau de conhecimento obtido pelas creditações $(61,9 \%)$ é ligeiramente maior em comparação com o obtido pela realização das UC na FMUP $(54,7 \%)$. Em relação às competências para ser médico os estudantes manifestam que é melhor realizar as UC na FMUP $(61,9 \%)$ em comparação à obtenção de creditações (50\%), apesar de preferirem as creditações. Em simultâneo estes estudantes afirmam que grau de conhecimento consegue-se sem frequência no currículo de medicina no entanto as competências adquirem-se no curso de medicina.

\section{Focus Group}

Quais os motivos de ingresso no curso de medicina e porquê da escolha da FMUP?

Neste primeiro tema foi possível apurar que, maioritariamente, a medicina foi sempre a primeira opção destes estudantes, e que as notas de ingresso foram o principal

Tabela 4 - Fatores associados com o número de créditos realizados durante a primeira inscrição no curso

\begin{tabular}{|c|c|c|c|c|}
\hline & & \multicolumn{2}{|l|}{ Ajustado } \\
\hline & $\beta($ IC $95 \%)$ & Valor $p$ & $\beta($ IC $95 \%)$ & Valor $p$ \\
\hline \multicolumn{5}{|l|}{ Idade } \\
\hline 22 a 25 & $6,28(-3,43 ; 16,08)$ & 0,214 & $13,31(4,53 ; 23,35)$ & 0,013 \\
\hline 26 a 29 & $12,92(4,60 ; 22,06)$ & 0,004 & $13,50(5,05 ; 22,53)$ & 0,010 \\
\hline 30 a 41 & Ref. & & Ref. & \\
\hline \multicolumn{5}{|l|}{ Género } \\
\hline Feminino & $12,81(4,13 ; 21,04)$ & 0,008 & $8,20(-2,51 ; 19,04)$ & 0,116 \\
\hline Masculino & Ref. & & Ref. & \\
\hline Créditos obtidos & $0,02(-0,11 ; 0,10)$ & 0,789 & & \\
\hline Satisfação com processo creditação & $-0,13(-0,35 ; 0,09)$ & 0,224 & & \\
\hline \multicolumn{5}{|l|}{ Satisfação créditos obtidos } \\
\hline Insatisfeito & Ref. & & Ref. & \\
\hline Nem insatisfeito/ Nem satisfeito & $-11,01(-23,05 ; 1,12)$ & 0,077 & $-5,14(-15,40 ; 4,78)$ & 0,324 \\
\hline Satisfeito & $-10,08(-18,88 ;-0,475)$ & 0,036 & $-9,73(-18,44 ;-1,63)$ & 0,031 \\
\hline \multicolumn{5}{|l|}{ Ano letivo } \\
\hline $11 / 12$ & $1,91(-7,50 ; 11,92)$ & 0,718 & $2,01(-8,67 ; 11,98)$ & 0,684 \\
\hline $12 / 13$ & $9,46(1,20 ; 18,23)$ & 0,038 & $6,58(-1,96 ; 16,04)$ & 0,162 \\
\hline $13 / 14$ & Ref. & & Ref. & \\
\hline \multicolumn{5}{|l|}{ Ciclo $1^{a}$ inscrição } \\
\hline Ano básico & Ref. & & Ref. & \\
\hline Ano clínico & $22,94(19,01 ; 27,40)$ & 0,001 & $34,92(20,83 ; 52,99)$ & 0,001 \\
\hline \multicolumn{5}{|l|}{ Grau } \\
\hline Licenciatura & $3,76(-4,79 ; 11,88)$ & 0,410 & $7,30(-0,50 ; 16,71)$ & 0,090 \\
\hline Mestrado Integrado & $12,74(2,03 ; 22,71)$ & 0,015 & $3,00(-5,00 ; 11,73)$ & 0,479 \\
\hline Mestrado, Doutoramento e Pós-doutoramento & Ref. & & Ref. & \\
\hline \multicolumn{5}{|l|}{ Área da Saúde } \\
\hline Não & Ref. & & Ref. & \\
\hline Sim & $13,65(5,49 ; 22,57)$ & 0,004 & $12,26(5,10 ; 19,42)$ & 0,001 \\
\hline
\end{tabular}


Tabela 5 - Preferência dos estudantes pelo reconhecimento por creditação à realização das unidades curriculares no currículo de Medicina da FMUP

\begin{tabular}{|c|c|c|c|c|c|}
\hline \multirow[b]{2}{*}{ Itens } & \multicolumn{5}{|c|}{ n (\%) } \\
\hline & $\begin{array}{l}\text { Discordo } \\
\text { totalmente }\end{array}$ & Discordo & $\begin{array}{l}\text { Nem concordo/ } \\
\text { Nem discordo }\end{array}$ & Concordo & $\begin{array}{l}\text { Concordo } \\
\text { totalmente }\end{array}$ \\
\hline $\begin{array}{l}\text { As creditações que obteve substituem o } \\
\text { conhecimento que obteria se realizasse as } \\
\text { unidades curriculares (UC) da FMUP }\end{array}$ & $0(0,0)$ & $8(12,5)$ & $8(12,5)$ & $32(50,0)$ & $16(25,0)$ \\
\hline $\begin{array}{l}\text { É preferível realizar as UC da FMUP do } \\
\text { que obter creditação }\end{array}$ & $10(15,6)$ & $30(46,9)$ & $18(28,1)$ & $6(9,4)$ & $0(0,0)$ \\
\hline $\begin{array}{l}\text { As creditações que obteve preparam-no } \\
\text { para o curso de Medicina }\end{array}$ & $0(0,0)$ & $3(4,7)$ & $5(7,8)$ & $45(70,3)$ & $11(17,2)$ \\
\hline $\begin{array}{l}\text { As UC realizadas na FMUP preparam-no } \\
\text { para o curso de Medicina }\end{array}$ & $0(0,0)$ & $1(1,6)$ & $6(9,4)$ & $37(57,8)$ & $20(31,3)$ \\
\hline $\begin{array}{l}\text { As creditações que obteve forneceram- } \\
\text { Ihe o mesmo grau de conhecimento em } \\
\text { comparação com os restantes colegas }\end{array}$ & $0(0,0)$ & $3(4,8)$ & $8(12,7)$ & $39(61,9)$ & $13(20,6)$ \\
\hline $\begin{array}{l}\text { As UC realizadas na FMUP forneceram- } \\
\text { Ihe o mesmo grau de conhecimento em } \\
\text { comparação com os restantes colegas }\end{array}$ & $0(0,0)$ & $1(1,6)$ & $9(14,1)$ & $35(54,7)$ & $19(29,7)$ \\
\hline $\begin{array}{l}\text { As creditações que obteve foram } \\
\text { suficientes para adquirir competências } \\
\text { necessárias para ser médico }\end{array}$ & $2(3,1)$ & $4(6,3)$ & $13(20,3)$ & $32(50,0)$ & $13(20,3)$ \\
\hline $\begin{array}{l}\text { A formação adquirida com as UC da FMUP } \\
\text { que obteve foram suficientes para adquirir } \\
\text { competências necessárias para ser médico }\end{array}$ & $0(0,0)$ & $1(1,6)$ & $7(11,1)$ & $39(61,9)$ & $16(25,4)$ \\
\hline
\end{tabular}

constrangimento de não ingressarem na sua primeira opção após o término do $12 .^{\circ}$ ano.

“(...) sempre quis medicina, também não consegui entrar por uma questão de nota, na altura optei por enfermagem, mas com o passar dos anos, percebi que de facto a vontade nunca tinha desaparecido, inclusivamente foi aumentando, e surgiu uma oportunidade para licenciados, achei que de facto podia tornar a tentar e como tal consegui e aqui estou." [Estudante_1]

Outros entrevistados acrescentam as experiências vividas nos cursos de origem manifestando a sua importância, mas colocando sempre a tónica e predileção pela medicina.

"Sempre quis medicina, tentei por dois anos, mas tive que ir para fisioterapia, por acaso gostei muito do curso (...), eu sempre trabalhei muito próximo dos médicos e era o que eu queria fazer. (...) quero ser feliz, para mim não tinha dúvidas, para mim era muito claro e, resolvi tentar de novo." [Estudante_2]

Através das representações de alguns entrevistados foi possível verificar que o exercício da medicina já não acarreta uma estabilidade financeira sólida como até então, foi visível o receio e a consciência da mudança, enquadrada num futuro próximo apesar da taxa de empregabilidade se manter ao nível dos 100\%:

"Não é por aquela lenda fantástica que o médico tem sempre trabalho, que o médico é o senhor doutor, eu quando voltei a pôr na cabeça que queria voltar a entrar em medicina, eu tinha perfeita noção que o panorama que eu iria encontrar se tivesse entrado no $12^{\circ}$ ano do panorama que eu ia encontrar efetivamente agora, ia ser bastante diferente (...) vou encontrar daqui a sete. Mesmo muito diferente, eu já começo a ouvir colegas que já saíram a dizer que os contratos que têm, ou outras propostas de trabalho que têm são a recibos verdes." [Estudante_3]

O curso de Medicina sempre foi o objetivo destes estudantes, quer por primeira opção, quer por decisão a posteriori com a constatação de alguma frustração com a sua primeira formação académica. A FMUP continua a ser a instituição mais escolhida, todavia a Medicina já não garante a mesma estabilidade financeira.

Relação com colegas e docentes e comparação das motivações e expectativas de ingresso

Neste ponto foi importante saber as opiniões destes estudantes sobre a sua relação com os colegas e docentes e abordar as motivações e expectativas. 
A relação com os colegas mais jovens é boa o que facilitou a integração.

"Eu por exemplo, da minha experiência, eu integrei-me bem, por exemplo, o meu grupo de estudo em anatomia quando nós vamos para o Teatro António, sou eu e mais dois colegas da turma que são digamos dos mais novos (...), no início talvez haja aquela coisa, embora eu pareça mais nova, também me chegaram a perguntar se queriam que me tratasse por "tu" ou por "você"..." [Estudante_4]

A postura em aula destes estudantes é distinta dos restantes mais jovens, é assumida com mais responsabilidade e focada na aprendizagem. A vida académica também é vivida de forma diferente, já não existe a necessidade de uma integração académica pós-aulas tão ativa.

"A diferença é, um caso prático, se eu estivesse mal em engenharia biomédica com 20 anos e um colega meu começasse a falar, eu distraía-me imediatamente com o meu colega que estava a falar e continuava a conversa, agora quando alguém começa a conversar à minha beira é uma coisa que me tira do sério porque eu quero ouvir o que estão a dizer e estou interessada em não me distrair. Para mim isso já quer dizer muita coisa." [Estudante_5]

Os fatores idade e regime de ingresso são apontados como elementos integradores, de elevada importância e de coexistência destes estudantes.

"Para mim foi inevitável que eu me identificasse mais com as pessoas que entraram pelo mesmo concurso que eu, com uma idade mais semelhante à minha e por isso... sim e também tenho outra expectativa, por exemplo, não me apetecia repetir a praxe, ter esse tipo de rituais académicos e a minha postura é completamente diferente da primeira licenciatura, mas acho que é uma coisa natural, não acho que seja uma coisa que não é normal." [Estudante_6]

Tendo em conta a relação com os docentes, os entrevistados não manifestaram de forma explícita a existência de uma relação estreita entre docentes e estudantes; no entanto, um estudante opinou sobre a postura dos docentes em relação aos licenciados:

"Os docentes, depende, tem os professores que admiram o nosso esforço e entendem, tem professores que aproveitam a nossa experiência de vida para fazer ganchos e estimular os alunos ou os outros colegas (...). Quando os professores, não sei porque não concordam com o acesso dos licenciados, não sei bem qual é a dificuldade, mas tem, professores que tem literalmente aversão, e tem aversão tipo, você está na aula e o professor pergunta quantos licenciados existem na aula? Parece que se sentem ameaçados por ter seis licenciados dentro da sala. Nós somos alunos iguais a todos." [Estudante_7]

Segundo Millan et al a faculdade é vista pelo estudante como o continente idealizado, onde não mais haverá angústia, insegurança ou exigências; pelo contrário, será o lugar onde suas expectativas serão satisfeitas e que possi- bilitará, finalmente, realizar o desejo de ser médico, muitas vezes presente desde a infância. ${ }^{15}$

Os estudantes manifestam a sua motivação intrínseca de querer ser médicos de uma forma muito afincada, associando ainda a certeza do que pretendem fazer no seu futuro profissional:

"No meu caso eu tenho uma motivação muito forte que é: eu já sei o que é que eu vou fazer quando terminar o curso, quer dizer, para mim uma coisa que me motiva muito é a minha realização profissional. Então eu sei que vou fazer o que gosto e para mim isso é uma grande recompensa, porque eu já trabalhei na área." [Estudante_8]

A certeza da escolha certa - a medicina - é uma tónica nos seus discursos, manifestam a convicção da sua escoIha, contudo a expectativa inicial em relação ao volume de trabalho exigido por este curso, foi defraudada.

"Em termos de motivação, mantém-se alta, porque eu cada vez estou mais convicta de que é isto que eu quero. Em termos de expetativas, eu já estava à espera de muito trabalho, costumo dizer isto, eu já estava à espera de muito trabalho, não tenho problemas com isso. Talvez, há aqui um grau acima de trabalho que eu não estava à espera." [Estudante_9]

O ensino da medicina no ciclo clínico - a partir do $4 .^{\circ}$ ano curricular - foi bastante criticado negativamente em relação às expectativas iniciais. Estes esperavam ter um papel mais interventivo junto do doente e nomeadamente na ajuda da resolução da sua doença. Apontam como constrangimentos para a não concretização dos seus objetivos a postura dos docentes, o número elevado de estudantes e o rácio estudante-tutor ${ }^{16}$.

"Eu de facto tinha expectativa no currículo por ser, os anos clínicos serem dado por módulos, mas fiquei relativamente desiludida, porque é uma utopia achar que passar para os módulos é mais prático, não, não é! Eu compreendo que nós estamos num hospital e que haja doentes e médicos e que funcione no hospital, mas na realidade também andamos num hospital universitário." [Estudante_9]

O ensino clínico arrasta consigo um enorme constrangimento, pois é um ensino essencialmente presencial e os que exercem uma atividade profissional terão obrigatoriamente que a interromper para frequentar o curso de medicina:

"A minha expectativa está baixa, porque é como lhe digo, aqui neste momento, no próximo ano eu estou a ver a minha realidade muito complicada e provavelmente vou ter que deixar de trabalhar." [Estudante_10]

\section{Qual o impacto das creditações obtidas no percur- so académico?}

Este tema vem na sequência da aplicação do questionário analisado, sendo que as entrevistas vêm colmatar os aspetos mais subjetivos e que complementam a investigação. 
Os entrevistados confirmaram o que já havia sido manifestado no questionário, isto é, preferem obter creditação em vez de realizar as UC no currículo médico, tornando assim os seus percursos académicos um pouco mais céleres. "Obtive imensas equivalências e isso foi bom no sentido em que me permitiu avançar mais e se sinto falta das cadeiras que fiz, de certa forma não, que por exemplo, genéticas, bioquímicas, biologias, foi uma coisa que para além daquilo que dei na disciplina em si na licenciatura, foram coisas que eu depois também acabei por ter que explorar e trabalhar, depois no mestrado e tudo o resto." [Estudante_11]

\section{CONCLUSÃO}

Os estudantes alvo do presente estudo já trazem consigo no ato de candidatura ao curso de Medicina, uma formação académica que Ihes proporciona uma integração e um percurso académico impar e célere.

Com a aplicação do questionário, e com as entrevistas dos grupos focais, podemos aferir que o reconhecimento académico de formação anterior é um elemento muito presente nos seus trajetos e com o qual estão satisfeitos. A satisfação com a creditação leva à realização de menos créditos no curso de medicina no entanto a idade mais jovem, a proveniência das áreas da saúde e a inscrição num ciclo mais prático origina maior sucesso académico. A preferência para obter creditação versus realizar as UC no curso de medicina coloca em questão o ensino-aprendizagem uma vez que há preocupação com o sucesso.

A socialização no meio académico é um pouco diferente dos restantes estudantes que ingressaram pela primeira vez, sendo mais focados nos objetivos, assumindo uma maior responsabilidade e manifestando que já não existe a necessidade de uma integração académica pós-aulas tão ativa.

As motivações de ingresso enumeradas são intrínsecas, não sendo indicadas quaisquer motivações conscientes como era inicialmente esperado. Subsistem elevadas ao longo do percurso académico e provavelmente consolidadas com as experiências vividas já no curso de medicina.

\section{REFERÊNCIAS}

1. Decreto-Lei n. ${ }^{\circ} 40 / 2007$. Diário da República, $1 .^{a}$ série $-N{ }^{\circ} 36-20$ de Fevereiro de 2007.

2. European Ministers of Education. Joint declaration of the European Ministers of Education - The Bologna Declaration of 19 June 1999. [consultado 2014 out 04] Disponível em: http://www.ehea.info/ cid100210/ministerial-conference-bologna-1999.html

3. Despacho n. ${ }^{\circ} 12722 / 2013$ de 4 de outubro. Regulamento de Creditação de Formação Anterior e de Experiência Profissional da Universidade do Porto.

4. Boruchovitch E, Neves ER. A motivação de alunos no contexto da progressão continuada. Psicologia: Teoria e Pesquisa. 2004;20:77-85.

5. Pinto A. Psicologia geral. Lisboa: Universidade Aberta; 2001.

6. Brim OG, Wheeler S. Socialization through the life cycle. In: Brim Jr OG, Wheeler S, editors. Socialization after childhood. Twoessays. New York: J. Wiley; 1966. p. 1-49.

7. Dubar C. A socialização. Construção das identidades sociais e profissionais. Porto: Porto Editora; 1997.

8. Weidman JC. Socialization of students in higher education: organizational perspectives. The Sage handbook for research in education: Engaging ideas and enriching inquiry. 2006:253-62.

9. Krueger RA, Casey MA. Focus groups: a practical guide for applied
As expectativas iniciais, aquando do ingresso, sofreram algumas alterações, destacando-se o volume de trabalho que se mostrou manifestamente maior do que o esperado, a dificuldade em conciliar o exercício laboral com o estudo na FMUP e a expectativa de um ensino clínico mais interventivo com o doente. Assim sendo existe a necessidade de uma análise aprofundada tendo em conta uma melhor adequação das condições pedagógicas no ciclo clínico.

Os estudantes que recorrem ao regime de ingresso concurso especial de acesso para licenciados - têm como pilar a vocação, ${ }^{17,18}$ a vontade de ser médico. A não conquista do ingresso em Medicina aquando o término do ensino secundário originou frustração e escolha de outras opções. No entanto, esta situação só veio fortalecer a sua vocação - a Medicina.

\section{AGRADECIMENTOS}

Ao Departamento de Ciências da Saúde Pública e Forenses e Educação Médica, à Direção do Ciclo de Estudos Integrado do Mestrado em Medicina da FMUP e a todos os estudantes participantes deste estudo.

\section{PROTECÇÃO DE PESSOAS E ANIMAIS}

Este estudo foi analisado e aprovado pela Comissão de Ética de acordo com a Declaração de Helsínquia da Associação Médica Mundial.

\section{CONFIDENCIALIDADE DOS DADOS}

Os autores declaram ter seguido os protocolos do seu centro de trabalho acerca da publicação dos dados de doentes.

\section{CONFLITO DE INTERESSES}

Os autores declaram não ter nenhum conflito de interesses relativamente ao presente artigo.

\section{FONTES DE FINANCIAMENTO}

Não existiram fontes externas de financiamento para a realização deste artigo.

research. Newbury Park: Sage Publications; 2009.

10. Krueger RA, Casey MA. Focus groups: a practical guide for applied research. Newbury Park: Sage Publications; 2014.

11. Morgan DL. Focus groups. Ann Rev Sociol. 1996:129-52.

12. Grbich C. Qualitative research in health: an introduction. Newbury Park: Sage Publications; 1999.

13. Morgan D. Focus group as qualitative research. Newbury Park: Sage Publications; 1997.

14. Bloor M. Focus groups in social research. Newbury Park: Sage Publications; 2001.

15. Millan LR, De Marco OL, Rossi E, Arruda PC. O universo psicológico do futuro médico: vocação, vicissitudes e perspectivas. Rev Bras Psiquiatr. 1999:83-94

16. Diogo PG, Moreira A, Coimbra A, Silva AC, Martins AN, Mendonça C, et al. Estudo sobre as condições pedagógicas das escolas médicas portuguesas: uma análise nacional sobre a satisfação estudantil, rácios estudante-tutor e número de admissões. Acta Med Port. 2016;29:301-9.

17. Blaya M. Dinâmica de grupo em psiquiatria. Alter. 1972;3:193.

18. Rocco RP. Relação estudante de medicina-paciente. In: Mello Filho J, editor. Psicossomática hoje. Porto Alegre: Artes Médicas; 1992. p. 4556. 